\title{
Riyazetten Modern Diyet Toplumuna: Kutsallık ve Hiçlik Arasında Beden
}

\author{
Sertaç Timur Demir*
}

Öz: Bu çalışma, ruhun kemalâtı için az yemeği öğütleyen riyazet çağından beden için diyet toplumunu yücelten modern çağa geçişi analiz etmektedir. Burada, hipotez olarak, ruh ve beden arasındaki ikircikli ve çatışmalı durumun, yerini insanın bedenîleştiği ve bedenin de hiçleştiği kollektif bir düzene bıraktığı öne sürülmektedir. Beden, tüm özgürleşme söylemlerinin ötesinde, modernitenin hem bitmeyen sermayesi hem de açmazına dönüşmüştür. Bu rejimde bireyler sıskalar ve şişkolar olarak kategorize edilirken; kendilik (the Self) gittikçe görselleşir. Öte yandan bu teşhir edici endüstrileşmiş görselleştirme beklenmedik biçimde tekrarlı, tekdüze ve algıyı körelticidir. Burada beden vurgulandıkça kaybolur. Mutluluk ve kurtuluşun salt spor salonu, zayıflama hapları ve diyet programlarına indirgendiği bu yeni yaşam formülü, bilhassa tıp bilimi ve medya aracılığıyla geniş kitleleri biteviye yeniden üretmektedir. Mutlak güzellik ve mutluluğa ermeyi amaçlayan her temayül yeni bir tatminsizlik ve sonsuz bir arayış olarak kendi küllerinden doğar. Bu çalışma, Meksika yapımı Malos Hábitos (2007) filmi üzerinden, bedenî ve manevi varlık, bireysel ve toplumsal beden, açlık ve oburluk, ayna ve görünüm, arzu ve tatminsizlik arasındaki ikiliklere odaklanmaktadır. Bu bakımdan, Türkiye'de son yıllarda sıklıkla tartışılan beden ve özgürlük kavramları etrafındaki seküler yorumlara zımni olarak eleştirel bir duruş da sunmaktadır.

Anahtar kelimeler: Modernite, beden, diyet, dönüşüm, kontrol, Malos Hábitos.

Abstract: This paper analyses - not chronologically, but sociologically - the transition from the age of asceticism, which advises one to eat like a bird in order to perfect the soul, to the modern age, in which the diet society is highlighted. It asserts that this ambivalent and conflictive situation between soul and body creates a collective regime in which the human being is embodied and the body becomes nothing. The body, being beyond all means of liberation, turns into both an unending capital and an abysmal swamp of modernity. Under this regime, the Self reflects upon itself and categorises the body as either skinny or fat. Besides, the exhibitive industrialised visualisation of the Self is unexpectedly blinding. Here, the body disappears as much as it is highlighted. The new style-life formula, which reduces bliss and salvation to the gym, slimming pills and diet programmes, incessantly guides the masses through the medical sciences and, in particular, the media. Every tendency towards achieving absolute beauty and happiness is reborn from its own ashes as a new form of dissatisfaction and leads to endless searching. Through the Mexican film Malos Hábitos (2007), this paper focuses on the dichotomies between physical and spiritual existence, the individual and the social body, hunger and gluttony, mirror and appearance, and desire and dissatisfaction. In this respect, it implicitly offers a critical stance of secular discourses focusing around the concepts of the body and freedom that have often been debated in recent years in Turkey.

Keywords: Modernity, body, diet, transformation, control, Malos Hábitos.

* Yrd. Doç Dr., Gümüşhane Üniversitesi, İletişim Fakültesi, Radyo TV ve Sinema Bölümü.

E-posta: stdemir@gumushane.edu.tr. Adres: Gümüşhane Üniversitesi Yerleşkesi, Illetişim Fakültesi Radyo TV ve Sinema Bölümü, Bağlarbaşı Mah., Merkez, Gümüşhane.

D0l: dx.doi.org/10.12658/human.society.6.11.M0160

İnsan ve Toplum, 6 (1), 2016 
"Yenen her şey iktidarı besler"

Elias Canetti

"Diyet toplumunda yenmeyen şey de iktidarı besler"

\section{Giriş}

Yemek bir zamanlar birliktelik oluşturan ve böylece evi yuvaya; aynı çatı altındaki dağınık bireyleri de aileye dönüştüren ortak ritüeldi. Şimdi ise ağırlıkla kişinin çevresinden ve hatta kendisinden koptuğu iletişimsizlik biçimini ifade etmektedir. Diyet çağında benlik (the self), Antony Giddens'ın altını çizdiği gibi (1991, s. 56), bedenîleşmiştir. Oysa bu beden artık bir şey değildir. Görüntüden ziyade her şey olmaya açık bir boşluk, bir belirsizliktir. Ne temsil edebilir, ne de temsil edilebilirdir; aksine beden imgesi, çıplak yani ifadesiz bir uzamdan başka bir şey değildir (Michaud, 2006, s. 357). Riyazet çağında bir tür öz-disiplini (self-discipline) ifade eden beden, diyet çağında başkaları tarafından kontrol edilmeyi ima etmektedir. Riyazet çağı, kitabî olsun ya da olmasın dinî temelli ve hususen az yeme, az konuşma ve az uyuma kaidesinin hâkim olduğu özellikle Ortaçağ gibi tarihsel bir periyoda gönderme yapmakla birlikte, daha ziyade belli bir felsefeyi ifade etmektedir. Tıpkı tarihsel boyutunun yanında tarihsellikten çok sosyolojik karşılığı olan modernite gibi, riyazet çağı da ruhsal tekamülü önceleyen bir yaşam tarzını karşılamaktadır.

Nefsin arzularının vücut bulduğu yer bedendir ve dolayısıyla beden kemalât yolunun en büyük mücadele sahasıdır. Riyazet düşüncesinde nefs, ruhun yanında beden üzerine geliştirilen kural ve pratiklere göre şekillenir. Daha açık bir ifadeyle riyazet felsefesinin beden politikası bedene dönüktür ama bedeni değil; ruhu hedef alır. Modernite ise, "az yeme" düsturuna dayanan diyet toplumunu üretirken, bedeni de yalnızca bedenin kendisi için yüceltir. Bu sebeple riyazet çağının hedef çıktısı ölüme hazırlanan zahit iken, modern toplumun ölümden kaçan fit bireydir. Modernitenin etkileri yalnızca Batı toplumlarına indirgenemeyecek denli yaygın ve geçerli olsa da, bedeni kutsayan diyet kültürü ve onun sonucu olan modern fit beden ve diyalektiği olan obezite çağdaş Batı dünyasıyla derinden ilişkilidir (Twigg, 2011, s. 229). Riyazet çağı ve modernite ikilemi, bu açıdan, bir tür DoğuBatı ayrımının kültürel dayanaklarından birini oluşturur. Buna göre, hızla yayılan beden miti, mekânsal farklılaşmayı anlamsızlaştıırcasına gündelik yaşamın, örneğin yemek kültürünün dahi aynılaşmasını — daha da açıkçası Batılılaşmasını ima eder.

Şu sıralar, yeni beden üzerinde bir tür kontrol-dışılıktan da bahsedilebilir. Hem bedensel hiçleşmeyi somutlayan anoreksiya hem de bedenin kendi sınılarından taşması anlamına gelen obezite, bu yeni ama sürekli değişen amorf beden formunu metaforize etmektedir. Beden gittikçe aşkınlaşmakta ve sınırlılık tanımamaktadır. O, yalnızca içinde yaşadığımız ve kendisiyle düşündüğümüz bir dışsallık değil (Becker, 1995, s. 34); bireysel modern kimliğin, içinde eridiği ve şekil bulduğu içkin bir potadır artık. Bu yeni beden ne ekonomik yetersizlik ve yokluk ne de bolluk ve doygunluğun ellerinde formüle olmaktadır. Obez olmak zenginliği ifade etmediği gibi, anoreksiya da bir fakir hastalığı değildir. Her ikisi de sınıf temeline dayalı birçok sosyolojik analizi boşa çıkarmaktadır. Bir tarafta kıtlığa rağmen şişenler; diğer tarafta bolluk içinde eriyenler vardır. 


\section{İstatistiki Arkaplan}

2011-2012 yıllarında Birleşik Devletler'de her altı gençten ve her üç yetişkinden birisi obezdi (Cynthia vd., 2014). 2013 yılında tüm dünyada beş yaşından küçük 42 milyon çocuk fazla kilolu (overweight) ve obezdi. 2014 itibariyle 18 yaşından büyük 2 milyar yetişkin kilolu ve bunların 600 milyonu obezdir. Obezite veya yüksel vücut kitle indeksi (body mass index) kalp ve damar hastalıkları, kas-iskelet sistemi hastalıkları, diyabet ve endometriyal, göğüs ve kolon kanserleri için en büyük risk faktörü olarak gösterilmiştir. Dünya Sağlık Örgütünün (World Health Organisation) 2015 raporunda belirtildiği gibi, obezite son 35 yıl içinde iki kat artmış durumdadır. Guardian'ın bildirdiğine göre (2015), obezite en fazla gelişmekte olan ülkelerde, özellikle de Ortadoğu, Latin Amerika, Çin ve güneydoğu Asya'da yaygındır. Bu sorunun arkasında, Birleşmiş Milletler Gıda ve Tarım Örgütünün (United Nations Food and Agriculture Organization) tespit ettiği gibi (2015), yemek tüketiminin Batılılaşması (westernization of food consumption) vardır. Neredeyse her dört erkekten ve her iki kadından birisi her gün diyet yapmaktadır (Sundgot-Borgen ve Torstveit, 2004). Oysa diyet konusunda geliştirilen çözümler, çoğunlukla sorundan daha büyük yaralar açmaktadır. İncelmek için atılan her adım, sağlıksız kilo kontrolü davranışları (unhealthy weight control behaviours) ve yeme bozukluklarına (eating disorders) eşlik etmektedir (Naumark-Sztainer, 2005, s. 18). Amerika'da yapılan kısmen eski ama oldukça çarpıcı bir araştırma (Grodstein vd., 1996, s. 1302), diyet yaparak kilo verenlerin yaklaşık yüzde 95'inin verdikleri kiloları 1 ile 5 yıl içerisinde geri aldıklarını göstermektedir. Öte yandan yine Birleşmiş Milletler Gıda ve Tarım Örgütünün raporuna göre dünyada kronik şekilde yetersiz beslenen yaklaşık 800 milyon insan bulunmaktadır. Bu sayı, istatistiklere göre, her geçen gün düşse de, Küresel Açlık Endeksinin (Global Hunger Index) 2015 raporuna göre yaklaşık 52 ülkeyi ciddi şekilde tehdit etmeyi sürdürmektedir. Bu sayılara başta Suriye, Sudan ve Somali olmak üzere iç-savaş kaynaklı açlık sorunu çeken milyonları da eklemek gerekmektedir.

\section{Yöntem ve Kuramsal çerçeve}

Bir zamanlar ruh için riyazeti önceleyen geleneksel pastoral dönemden, "önce ve hep beden"i kutsayan modern diyet çağına geçilmiştir. Fakat bu gelinebilecek son nokta değildir. Bu çalışma, diyet kültürünün dokusunu, imkânlarını, etkilerini, sonuçlarını ve muhtemel akıbetini incelemeyi amaçlamaktadır. Bu maksatla, izlenen ve izleyici olarak bedene, yıkıcı ve yapıcı olarak yeme praksisine, modernitenin zımni kıstası olarak incelik ve obeziteye, üretici ve tüketici kültür olarak diyet endüstrisine odaklanılmaktadır. Yöntem olarak, Malos Hábitos filminden hareketle ama bütünüyle filme bağlı kalmadan beden imgesi, incelik/ şişmanlık, ideal beden, kontrol, yeme bozukluğu, biyomedikal endüstri, kendilik ve ötekilik olarak beden gibi alandaki güncel kavram ve tartışmalara yer verilmektedir. Çalışmanın kuramsal çerçevesi ağırlıkla Jean Baudrillard, Michel Foucault ve Bryan Turner gibi bedeni kendi varoluşsal dokusundan ayırıp, onu toplumsalın göstergesi ve modern ilişki ağlarının merkezi olarak ele alan düşünürlerin etrafında kurgulanmıştır. Buna göre, Baudrillard'ın bakışında beden, hakikatini yitiren ve simülatif görünümlere dönüşen gerçekliğin felsefi temsilsizliğini ifade ederken (1993, 1998, 1999, 2004); Foucault için iktidar ilişkilerinin vücut bulduğu bir projeksiyona gönderme yapar $(1971,1973,1977,1979)$. Turner ise, genel manada, bedeni tıbbileştirilen modern toplumun sermaye koşullu bir yapbozu olarak tartışır (1995). Her üç yazar için de beden, en son olarak bedendir. Tene ve maddeye indirgenmiş 
bir beden tasavvurundan ziyade; onlar için beden, sakladığı ve ifşa ettiği asıl gerçekliği analiz edilebilir yapan bir tür aynadır. Bu çalışmada da beden, tam da bu üç düşünürün paralelinde, riyazetten diyete doğru evrilen toplumsal hareketliliği sorgulamak maksadıyla bir tür temsiliyet bağlamında ele alınmaktadır. Malos Hábitos filminin analizi üzerinden bu çalışma, hâlihazırda her geçen gün daha fazla popülerleşen yemek (eating), diyet ve beden çalışmalarına bir tür katkı olarak değerlendirilebilir.

Analiz yöntemi olarak filmin seçilmesi de, bedeninkine benzer ve en az beden kadar felsefi derinliği olan bir araçsallık içerir. Nitekim film sanatı tekniğe dayalı olsa da, modern Batı'da Nietzsche, Wittgenstein ve Heidegger ile biten felsefenin yerini alan sinema (Kaplan, 2009), başlı başına sosyal bilim yapmaya denk düşmektedir. Film, mekâna ve toplumsala anahtar deliğinden bakmaya benzetilebilir (Demir, 2014, s. 28). Görünmeden görülenin kendisi varlığın manipülatif görüntüsü olsa da, gözün ve ışığın ulaştığı yerde gerçek belki de en doğal, yalın ve çıplak haliyle orada belirir. Bu yönüyle film, yalnızca filmden ibaret değildir. Bu çalışmada da Malos Hábitos filmi, yalnızca hikâyesi ve senaryosuyla değil; tasarladığı karakterler, geliştirdiği kurgu ve kullandığı sinemasal tekniklerle riyazet ve diyet ikileminde karşııı bulan küresel bir dönüşüme dair optik yakınlaşma (zoom in) sağlamaktadır.

\section{Malos Hábitos filmine dair}

2007'de Simón Bross tarafından çekilen Malos Hábitos (Kötü Alışkanlıklar) filmi en basit ifadeyle 'yemek' hakkındadır. Filmde öne çıkan dört karakter - Matilde, Elena, Linda ve Gustavo- ve birbiriyle kesişen, birbirini derinden etkileyen hikâyeler vardır. İlk karakter Matilde, doktora derecesini aldıktan sonra rahibe olur. Açlık ile iman arasında ilişki kuran genç Matilde, yemekten feragat etmeyi kötülüklerle mücadele etme aracı olarak konumlandırmıştır. Böylece Meksida'da beklenen büyük tufanı da engellemeyi umar. Elena'ysa, anoreksiya hastalığına müptela, sürekli olarak ayna karşısında bedenini seyreden, mütemadiyen tartılan ve koşu bandının üstünde vakit geçiren varlıklı bir kadındır. İskeletini örten et yığını, onun gözünde yok edilmesi gereken bir fazlalık, aşılması gereken bir tümsektir. Şişmiş ve pörsümüş bedenlere dair duyduğu nefret, kızı Linda üzerinde uyguladığı baskıda da açıkça görülür. Aynı zamanda Matilde'nin de öğrencisi olan Linda oldukça şişmandır ve zayıflamaya dair tüm kuralları boşa çıkartır. Yaklaşan komünyonda giyeceği kıyafetlerin içine sığmak zorunda olduğundan, annesi Elena tarafından sıkı bir diyete zorlanan Linda, "şişmanları kimse sevmez" gibi keskin yargılara sık sık muhatap olur. Zayıflama klinikleri, akapunktur seansları, zayıflama ilaçları gibi arayışların içine girer. En son, midesine kelepçe taktırmayı dahi tasarlar. Ne var ki, bu girişimlerin hiçbiri sonuç vermez ve uyguladığı baskılar sonucunda Elena, hem kendi hayatını hem de eşi Gustavo'yu kaybeder. Gustavo mimardır ve Elena'nın aşııı zayıfığından ve yemeye karşı takındığı kısıtlayıcı tutumdan rahatsızdır. Birlikte yemek yeme ritüelleri seyrekleştikçe aile bağları da zayıflar. Gustavo, kilolu ve oldukça iştahlı bir öğrencisiyle ilişki yaşamaya başlar. Filmin sonunda, kopan tufan ve yağan şiddetli yağmur Gustavo'nun sorumlusu olduğu binayı bastığında, artık yaptığı yanlıştan dönme vaktinin geçtiğini anlar. Bu tufan, yalnızca Gustavo'yu değil; Matilde'nin de sağlığını ve kuvvetli inancını, yaptığı riyazetle kurtarmaya çalıştığı insanlarla birlikte enkaza çevirir. Yemek üzerine geliştirilen tüm stratejiler açık bir şekilde işlevsizleşmiştir. Buna rağmen, yemek ekseninde tartışılan beden —özelde incelik (thinness) ve obezite- küresel olarak modern dünyanın ve çağdaş sosyal bilimlerin en güncel sorunlarından birine gönderme yapmaktadır. 


\section{Beden Üzerine}

Film, yemek masasının etrafındaki aile üyelerinin flashback görüntüsüyle başlar. Nezih bir sofra, mutlu bireyler, hoş sohbet. Başta her şey yolunda gözükür. Daha sonra peder Ramon'un boğazına lokma kaçar. Uzun bir müddet nefes alamaz. O sıralar küçük bir kız olan Matilde, o an Tanrı'ya onu kurtarması için dua eder. Bu küçük kız, Ramon'un kurtulduğunu gördüğünde yemekler ile olaylar ya da daha doğrusu beden ile inanç arasındaki mucizevi ilişkiyi de keşfetmiş olur. Ne zaman kötü bir olayla karşılaşsa, bir tür yakarış ve yakınlık cihetinden kendisini açlığın kollarına bırakır. İlerleyen yıllarda, halası yoğun bakımdayken de yaptığı budur; yine muvafık olur. Son imtihan, Meksika'da beklenen büyük tufandır. Günlerce yemek yemez. Diğer rahibelerin dikkatini çekmemek için yediği ufak tefek kırıntıları da gizlice istifra eder. Ne var ki, tufan tüm Meksika'yı yerle bir eder ve hem sağlığından hem de inancından olur. Bu hazin sona rağmen, Matilde takındığı tavır ve yönelimle birçok kadim dinin önemli bir öğretisini gündeme getirir. Bu öğreti, genel olarak, yemenin nefsi şımarttığı, kulluğun huşusunu ve ibadetin samimiyetini zevale uğrattığı düşüncesine dayanır. Riyazet fikrinin önemli ritüellerinden biri olan orucun ardındaki sebep, yine, bedeni ası sahibi olması gereken ruhun terbiyesine devretmektir. Burada az yemekten anlaşılması gereken de bedenin bir nevi ezilmesi veya aşağılanması suretiyle teskin ve kontrol edilmesidir. Yıllarca özgürlüğün karşı-metaforu olarak ele alınmış olan beden, bugün, oysa, modern insanın hem en görünür hem de en müphem açmazlarından biridir.

Özellikle Foucault'nun (1977) iktidar ilişkileri çerçevesinde tartıştığı beden, bir kısım gözetim politikalarını hem harekete geçirmekte, hem de kalıcı ve uzun vadeli çözümleri askıya almaktadır. Baskı ve cezalandırma aracı olmaktan çıkan beden, bugün, bir tür özel mülkiyet ve yatırım nesnesine dönüşmekte ve aynı anda hem defalarca ticari karlılık unsuru olarak piyasaya sürülmekte; hem de paradoksal olarak değersizleştirilmektedir (Lefebvre, 2005, s. 128). Gerçekten de, modern toplumda "vurgu" yok edicidir. Bir şey tamamen kaybolmadan hemen önce en yüksek ışıltısıyla öne çıkartılır. Bu sebeple göstermek (pornografileştirmek), bu anlamda teşhir etmek değil; onu hiçleştirmektir. Ya da Baudrillard'ın ifade ettiği gibi (1998, s. 106), sürekli yinelenen göstergeleşmiş çıplaklık (nudity), vücudu salt bir fantazma derekesine indirir. Bedenin yeniden üretilirliğinin öngörülebilirliği yoktur artık. O, sonsuz esneklik ve çözünürlük kapasitesiyle olmadığı her şeye dönüşebilmektedir. Beden bu diyet çağında müthiş bir dışsallık sergilemektedir. Onun için mutlak bir mekân ve zaman tayin etmek muhaldir. Aynı anda her şey olmaya açık bir muğlaklığıyla, gösterilen ideal ölçüler doğrultusunda devamlı hareket etmektedir. Sebepleri meçhul, sonuçları muğlak bir akışkanlığın içine kendisini bırakmış gibidir. Buna rağmen, beden bireysel kimlik duygusu için her geçen gün daha fazla merkezîleşmektedir (Shilling, 1993, s. 1'den akt. Turner, 1995, s. 274). O, yalnızca içinde bulunduğumuz bu çağı değil, her dönemin değer yargısı, inanç ve pratiklerini görünür ve analiz edilebilir yapmaktadır. Örneğin riyazet çağında beden ruhun zehiri, sonraları ruhun temsili ve aynasıyken (Synott, 1993; Shilling, 1993'ten akt. Turner, 1995, s. 236); bugün belki de ruhun kendisidir.

Bedenin etrafını kuşatan sağlık, perhiz, tedavi kültü, gençlik, zarafet, erillik/dişilik takıntısı, bedene uygulanan bakımlar, rejimler, fedakârane girişimler, bedeni kuşatan arzu söylemi, tüm bunlar günümüzde bedenin nasıl bir kurtuluş nesnesi haline geldiğinin tanığıdır. Bu ahlaki ve ideolojik işleviyle beden tam anlamıyla ruhun yerini almıştır. (Baudrillard, 2004, s. 105) 
Beden ve ruh arasındaki bu iç içe geçiş, ironik bir biçimde çatışmanın olanaksızlığını ima eder. Oysa zühdün sınırlarını aşmış beden, daha önce belirtildiği gibi, riyazet felsefesinde kemalâtın önünde kadim bir engelleyicidir. Örneğin Erzurumlu İbrahim Hakkı̀nın Marifetname eserinden yararlanarak çok yemenin zararlarını sınıflandıran Göktaş (2012, s. 50), bedene indirgenmiş bireyin manevi kalbi katılaştırıp kararttığından bahseder. Dahası böyle birisi çok konuşmaya ve çok uyumaya eğilim gösterir. İlmi, idraki ve ibadet zevki azalır. Bu sebeple riyazetin denetimindeki beden ruhsal terbiye kadar hazzın da özüdür. Modern bedense, mutlu birey kültünün hem kendisi hem de diyalektiğidir. $\mathrm{O}$, bugün, bu denli müphem karşı koyuşa rağmen, kendisinden başka antitezi ve panzehiri olmayandır. Yaşam ve ölüm beden için ya da bedene karşı değildir artık; onun içinde ve onunladır. Her ikisi bedene dönüştürülmüş, sıkıştırılmış ve dolayısıyla hiçleşmiştir. $O$, yaşamla ölümü karşı karşıya koymaz, aksine fanilik ve ölümsüzlüğü aynı potada eritir ve böylece kırılgan-olmayan/esnetilebilen yeni bir değer üretimine kapı aralar.

\section{Beden Kaideleri}

Beden, nihai formu olmayan, üzerinde oynadıkça bozulan, bozuldukça yeniden inşa edilmeye tabi tutulan bir kurgusallıktır. İncelik, bu açıdan, fiziksel görünüşün ötesinde, belki de çağın metaforudur. Riyazet çağında incelme, pazarlanan bir görünümden ziyade tenin ölümlülüğünün ve ruhun cismani varlık üzerindeki hâkimiyetinin kutsal bir dışavurumuydu (Seid, 1991, s. 50). Bugünse kendine güvenin yansımasına dönüşmüştür. Öyle ki çoğu modern birey için daha ince olmak daha çekici (Haworth-Hoeppner, 2013, s. 97-102), daha özgür (Fraser, 2009, s. 13), daha sağlıklı (Isono vd., 2009, s. 128) ve üst-tabaka (Hesse-Biber, 2007, s. 115) olmaya eşdeğerdir. Bu formül ters çevrildiğinde; sağlığın, mutluluğun, cazibenin, özgüvenin, özgürlüğün ve yüksek statünün yolunun incelmekten geçtiği de iddia edilebilir. Buna uygun olarak da, "incelmenin Eurocentric ve Anglo idealleri" (Burns-Ardolino, 2009, s. 273) olmazsa olmaz bir başarı göstergesi ve bireysel sorumluluğun bir yansıması olarak yorumlanır (Guthman, 2009, s. 193). Bu noktada belirtmek gerekir ki, bu Batı merkezci beden ince ve beyazdır (Baker, 2015, s. 45). Hesse-Biber (1996, s. 11) inceyi (thin) kutsal, güzel, sağlıklı ve mutlu olarak tanımlar. O kadar ki, kurtuluş hedeflenen kiloyu (target weight) elde edenleri beklemektedir. Ona göre, şişman bayağıdır; şişman olmak çirkin, güçsüz, tembel, pejmürde ve amaçsız olmaktır. Hesse-Biber son noktayı sert bir şekilde koyar: "düzgün bir kiloya ulaşmak bireysel mesuliyetin ötesinde; ahlaki mecburiyettir" (1996).

Her gün daha fazla geliştirilmiş formüllerle desteklenen ve teşvik edilen bu kategorize edici oyunda bir kısım kaideler vardır. Bunlardan ilki, tavsiye edicinin satıcı, muhatabın ise müşteri olduğudur. Bu kural, Adorno ve Horkheimer'ın tespit ettikleri gibi (1997, s. 147), endüstrinin insanla yalnızca müşteri ilişkisi kurduğu fikrine de dayandırılabilir. Beden üzerindeki hiçbir politika doğrudan ve ilk olarak bedenin sahibine/taşıyıcısına hizmet etmez. Aksine o, hedeflenen endüstriyel sonuca ulaşmada en banal haliyle araçsallaştırılır. İkincisi tıp bilimi ve sağlık endüstrisi aracılığıyla beden imgesine karşı verilen mücadelenin ardında ölümü kabullenmeme temayülü vardır (Castells, 2000, s. 482). Başka bir ifadeyle, bedenle onu taşıyan birey arasındaki yağ ve kalori savaşının özünü ölüm ve belki ondan da beteri yaşlanma korkusu oluşturur. Ölüm, kendi başına geliri düşük bir ticarettir ve tüm beden politikalarını haklılaştıran çirkin yaşııı̆ıı sonu ve yok oluşudur. Fakat ölümü ötelemeyi amaçlayan her girişim, beden endüstrisinin aynı zamanda bitmeyen sermayesidir de. Zira her başarısız 
deneme, hep daha etkili olduğu varsayılan yeni formülleri gerekli ve geçerli kılar. Bireyi bedeni üzerinde tek söz sahibi kıldığı iddia edilen bu endüstrinin bedeni güzelleştirmek, iyileştirmek ya da gençleştirmek adına piyasaya sürdüğü her türlü ürün ya da yöntemin çoğu zaman başarısız olmasına rağmen meşru görülmesi bundan olsa gerek.

Öleceği güne kadar mümkün olduğunca genç görünmeye çalışan modern birey, yaşlılıkla ve yaşılığın izleriyle olan anlaşmasını ölümün gelişiyle birlikte kaçınılmaz olarak fesheder. Genç kalmak değilse de, genç görünmenin medikal çözümleri, bu sebeple, ölümün gölgesinde mutlak başarı vadedemez. Beden politikasının, ölümü yaşamın dışsal bir anı ve ölenleri de yaşayanların ötekisi olarak konumlandırmasının nedeni budur. Gidenlerin açtığı boşluk bir an evvel kapatılmalı ve akışkan ilişkiler sekteye uğramadan devam ettirilmelidir. Riyazet çağında, ölen, geride kalanlara belirsiz sıranın kendilerine yaklaşmakta olduğunu ifşa ederken, bugün ölüm olancasına uzun ve sağlıklı yaşam tarafından bastırılmaktadır. Ölenin ardından kullanılan dil de, geride kalanların ölenle birlikte kalkıştığı birkaç günlük ortak zihinsel yolculuğu engellemek ister gibidir: "Hayat devam ediyor".

Bedene, bedenle, bedene rağmen ve beden için geliştirilen her geçici çözüm, farklı ve fakat hepsi bir diğeriyle ilişkili hazır paketlere iliştirilmiştir. Üçüncüsü, daha önce belirtildiği gibi, bedenin alabileceği nihai ve en iyi durumsallık söz konusu değildir. Beden, yeni trendlerle sürekli olarak hareket halinde, çoğu başarısız değişime tabi tutulur. Buna rağmen, her geçen gün yeni diyet tarzları, yeni formüller türemektedir. Beden tatminsizliğinin göstergesi olarak bireyler aynalara bakarlar, tartılırlar, bedenlerinin belli bölgelerini ölçerler, kilo vermek ve dolayısıyla görünüşlerini değiştirmek amacıyla egzersiz yaparlar, olağandan az yerler, sıkılığını ve canlılığını yitiren bölgelerine losyonlar sürerler (Castilho, 2006, s. 30-31), tamamı 'doğal' kürler uygularlar. Işık hızıyla hareket etmeye eğilimli olan bu bedenler için (Ory, 2006 , s. 114) hedeflenen ideal kilo veya arzu edilen görünüm, ne kadar çaba sarf edilirse edilsin, hep aynı uzaklıkta kalır. Her estetik müdahale bedensel güzelliği vadederken; aynı zamanda beden hakkında sonu gelmeyen bir eksiklik ve yetersizlik duygusunu da yerleştirir.

Dördüncüsü, günümüz toplumunun aynası ekrandır ve tıbbın beden ölçüleri hakkındaki özgüven dolu mesajları ekran sayesinde hastane koridorlarından taşmıştır. Medya bir yandan inceliği tavsiye ve tahkim ederken (Perse, 2001, s. 184), aynı zamanda beden tatminsizliğine (body dissatisfaction) neden olan toplumsal karşılaştırmayı da doğallaştırır (Fischer vd., 2006, s. 162). Higgins tarafından 1987 yılında öne sürülen "özbenlik çelişki teorisi" (selfdiscrepancy theory), kendisini başkalarıyla kıyaslayan bireylerin kendisi dışındaki 'ideal' ölçü veya norma doğru hareket edeceğini ve olası bir uyumsuzluk durumunda da kaçınılmaz olarak hayal kırıkığına uğrayacağını iddia etmektedir (akt. Fedorak, 2014, s. 72). Bununla bağlantılı olarak, beşincisi, beden toplumsal-olarak inşa edilen kolektif bir projedir. Burada başkalarının bedeni, benim bedenim üzerinde belirleyici mihenk taşıdır. Başkasının bedeni olmadan kendi bedenimi belirleyemem (Ancet, 2008, s. 81). Bunun için zayıflamaya ya da beden transformasyonuna dair paylaşılan başarı hikâyeleri, videolar, haberler, ürün tanıtımları benim bedenimi kuşatır. Diyetten "önce" ve "sonra"ya ait imgeler, beni kendi fazla ya da yetersiz imgem üzerinde değişime zorlar. Bu, beden anksiyetesinin başladığı noktadır ve bu tutkulu gerilim kadınlarda incelme, erkeklerde ise genellikle kaslılık yönelimi olarak tecelli eder (Smolak, 2011, s. 69). Filmin zayıflama baskısını üzerinde en fazla duyumsayan karakteri olan Linda'nın hissettiği bu baskının büyük bir kısmı, esasında tam da bu kuşatmadan 
kaynaklanır. Bu koşullar altında, Linda başkalarının bedenleri üzerinden kendi aşıı bedeni hakkında yıkıcı şekilde olumsuz yorumlama yapar (Qvortrup, 2010, s. 14). Son olarak altıncıSI, Linda için onun bedeni —esasında herkes için herkesin bedeni, hastalık ve risklerle dolu ve kusurlu görülür. Çünkü beden imgesinin kusurlu ve hastalıklı görünmesine sebep olan ideal bedenin kendi hakikati, sorgulanamayacak denli uzaktadır ya da kasıtlı olarak uzak tutulur. Bu uzak kusursuz imge filmlerde, fotoğraflarda ya da reklam afişlerindedir. Uzak tutulur, zira genelde şöhretlere ait olan bu ideal bedenler, değerini —daha doğrusu arzulanırlığını- açıkça-görülür fakat kesinlikle-yakınlaşılamaz oluşundan alır. Star olmak yıldızlar kadar uzak ve erişilmez olmak demektir. Hiç şüphesiz ki, şöhret kalkanının aşılıp bedensel yakınlığın sağlanması, cilalı yüzeyin, parıltılı vitrinin ve göz alıcı makyajın kışkırttığı ayartıcı büyünün çözülmesidir.

\section{Beden Kurumları}

Modern toplumda hemen her birim, nesne ve ilişki beden bağlamında kurumsallaşmıştır. En iyi planlanmış denetim ve gözetim süreçlerini dahi gölgede bırakan bu kendinden menkul mekanizmada, her birey aileden arkadaş ilişkilerine; okuldan hastaneye; bilimden teknolojiye; televizyondan sokağın her köşesinde modern beden politikalarından yüzeysel manada etkilenmekle kalmayıp, söz konusu mekanizmayı işleten birer dişliye dönüşmüştür. Filmdeki karakterler ve onları çevreleyen sosyokültürel ve ekonomik ağ, bu akışkan sistemi belirginleştirmektedir. Örneğin, filmin karakterlerinden Elena varlıklı bir kadındır. Zayıftır ve daha da zayıflamak istemektedir. Kendi bedeninin detaylarındaki 'kusurlara' odaklandıkça çevresine karşı körleşir. Sonsuz bir incelme arzusuyla hayatı yalnızca kendisine değil, eşine ve kızına da zehir eder. Diğer karakterler Gustavo ve Linda, Elena'nın aksine, yemekten oldukça haz alırlar. Şişmanlamaktan korkmazlar. Onlar için yemek yemek bir tür özgürleşme veya kendini gerçekleştirme praksisidir. Elena, Gustavo ve Linda arasındaki bu farklılaşma, kısa zaman içerisinde mutlu evliliğin temellerini yerinden oynatır. Elena vaktini koşu bandı üstünde geçirirken, Gustavo yemekten keyif alan bir öğrencisiyle ilişki yaşar. Yüzeysel şekilde gösterilen hikâyesinde Gustavo, film boyunca bu öğrencisiyle tümüyle beden odaklı vakit geçirir; yemek yer ve yatar. Yönetmene göre, yemenin önüne konan tüm radikal engelleyiciler kilonun sebep olabileceği hastalıklardan çok daha fazla yıkıcıdır. Bedensel bir ritüelin ötesinde, anlam ve göndermelerle yüklü olan yemek yeme hali, yönetmenin gözünde, birleştirici, bir araya getiricidir. Nitekim sözcükler ve besinler arasındaki ilişki karşılıklı-varedicidir (Falk, 1994'ten akt. Turner, 1995, s. 237). Bryan Turner burada bireyselleşme ile bireyselleşmiş beslenme arasında doğrusal bir analoji kurarak, yeme alışkanlıklarıyla toplumsal düzen arasındaki belirleyiciliğe dikkat çeker (1995, s. 238). Ona göre, yemek toplumsal ilişkilere dâhil olmaktır ve modern toplum kolektif beslenme ritüellerinden uzaklaşarak bireyselleşmiş beslenmeye geçmiştir. Diyet, bu anlamda her ne kadar kapsamlı tavsiyeler ve çoğul ifadeler barındırsa da, eylem olarak tek başınalığı besler. Daha ince olmak adına atılan her adım, daha fazla kendine odaklanma ve izolasyon sebebine dönüşür. Elena'nın yemekten uzaklaşırken, eş zamanlı olarak ailesi ve gündelik ilişkilerinden de uzaklaşması bu sebepledir. Yeterince zayıftır ama daha zayıf, daha güzel, daha özgür, daha mutlu olmanın, evvelce vurguladığımız gibi, bir varış çizgisi yoktur ve olmayacaktır. Yönetmen, Elena üzerinden, "alımlı kadın, zayıf kadındır" ve "şişman, toplumun ötekisidir" kabilinden popüler kültür klişelerini eleştirmek ister gibidir. Gerçekten de şişman, modern toplumda her şeyi içine alırken dışarıda kalan ya da bırakılan kişidir. Gustavo'nun kendisi gibi şişmanlar topluluğun- 
dan birisine yönelmesi neden bir bakıma 'içeriye dâhil olma' arzusu olarak okunmasın? Zira beden ölçüleri ekseninde çizilen küresel sınırların dışında kalan bir şişmanın, kilo vermek dışında yapabileceği en iyi şey, kendisi gibi dışlanmış şişmanların da içinde bulunduğu yeni bir sınır hattı çekmektir. Bu bedensel gettolaşma, tüm kimlik politikalarında olduğu gibi, yalnızlıktan ve ötekileştirilmekten kurtulmanın en kolay yoludur. Ne var ki, bu gettolaşma mekânsal farklılaşmadan ziyade zihinsel ayrışmayı ifade eder ve çoğu zaman bir teselliden öte gidemez.

Öte yandan, şişmanlık bir yandan modern toplumun nasıl da ölümcül doyum üzerine kurulu olduğunu betimlerken (Baudrillard, 1993, s. 32) aynı zamanda dışlanması yoluyla ideal beden rejiminin sınır çizgilerini de tayin eder. Modernite, şişmanı aynı anda hem üretmiş hem de lanetlemiştir. Her savaşta dışarıdaki düşmanla ve cephe gerisine yerleştirilmiş düşman ajanlarıyla savaşıır. Bauman ise şişmanlığı, savaşta cephe gerisine yerleştirilmiş düşman ajanlarına benzetir (1999, s. 45). Bedenin temsili yoksa da, şişmanlığın temsili vardır. O, bu çağda yavaşlığı, tembelliği ve hastalığı temsil eder (Seid, 1991, s. 17). Tıp perspektifinden şişman, yaşamsal olanı da yemiştir ve ölümle burun buruna yaşar. Diyet, bu sebeple, ölümlülüğün çözümü —değilse en azından diyalektiği olarak sunulur. Baudrillard, basit bir olumsuzlamanın ötesinde, obezi, içinde yaşadığımız hiper-gerçekliğin bir prototipi, çerçevesi iyi çizilen döngünün nihilist bir ifadesi olarak görür (1999, s. 27). Obez, modern toplumda cinsiyetsizleştirilmiş ve cinsellik politikalarından muaf tutulmuştur (1999, s. 30). Buna rağmen, bir hiper-gerçeklik olarak obez $(1999$, s. 34) her şeyi kendi tapusuna geçirir ve kendisine ait olmayanı ayırt edemez (1999, s. 30). Bu, filmde Gustavo'nun açgözlülüğüyle vücut bulur. Oburluk ölümcül kötülüktür ve felaketlerin kaynağıdır. Belki de bu sebeple, Gustavo'nun yaptığı bedenseli kutsayan kaçamaklar, mimarı olduğu binanın sular altında kalmasıyla son bulur. Linda'ya gelince, o, daha önce belirtildiği gibi, annesi tarafından incelmeye — daha açıkçası ideal bir bedene sahip olmaya zorlanır. Bunun için yüksek bedeller ödeyerek zayıflama endüstrisinin tüm hizmetinden faydalanır. Ancak sonuç başarısızdır. Yeme dürtüsüne engel olamayan Linda, annesinden gizli tüketmeyi sürdürür.

Linda'nın gittiği zayıflama merkezinde zayıflama hayaliyle yaşayan, tektipleşmiş, bedenlerine odaklı şişman kadınlar vardır. Belirlenmiş ölçülerle yerler, belli aralıklarla ve topluluk içinde tartılırlar. Aldıkları mesafeyi görünce kendilerinden geçip; yeteri kadar incelmediklerinde kendilerini kınarlar. Baskül, burada, basit bir beden-ölçer olmanın ötesinde, mutluluğun kıstasına dönüşmüştür. Belirlenmiş ideal beden ölçülerinden taşan yerleri hem kendileri hem de kilo gözcüleri (weight-watchers) gibi yaşadıkları cemiyet içinde açık bir leke gibi görünür. Bauman'a göre (1999, s. 46) parçalarının toplamından daha büyük olmayan kilo gözcüleri, tek sesli bir koro gibi, aynı şeyi hep birlikte ve aynı tonda ifade ederler. Ortak bir dine mensup kişiler gibi, paylaşılan bir uzamda aynı ritüeller etrafında bir tür ayin —zayıflama ayini yaparlar. Her biri farklı başarı oranına sahip olsa da, kendilerine sunulan menüye ve programa ibadet vecdiyle gösterdikleri bağlılık dikkat çekicidir. Diyet ve egzersizlerle çeşitlendirilmiş programa dâhil olarak hem bedenleri için hem de bedenlerine karşı mücadele ederler. Esasında ulaşılabilecek mükemmel bir ölçünün olmadığı, hedeflenen kiloya erişildiğinde de bunu korumak adına devamlı kontrolün gerekli olduğu bir kısır döngüde, daha önce de altını çizmeye çalıştığım gibi, savaşın kesin bir sonucu ve mutlak bir sonu olmayacaktır. Bu, Chul-Han'ın kavramsallaştırdığı performans toplumunun temel karakteristiğidir (2015, s. 10-11). Ona göre, spor salonları, bürolar, gökdelenler, bankalar, havaalanları, alışveriş mer- 
kezleri ve gen laboratuvarları, Foucault'nun yıllar evvel bahsettiği hastaneler, tımarhaneler, hapisaneler, kışlalar ve fabrikalardan oluşan disiplin toplumunun yerini almıştır. 21. yüzyıl toplumu artık disiplin toplumu değil, performans toplumudur. Modern birey de itaatkâr özne değil; performans öznesidir (2015, s. 8). Dışsal bir öteki ya da hastalıkla değil, kendi kendisiyle savaşan performans öznesi, "her şeyin mümkün olduğu" bir çağda bitmeyen bir takıntı ve mutsuzluk nöbetlerine müpteladır. Fakat bu da Foucault'nun tartıştığı (1971, $1973,1977)$ panoptizm veya disiplin toplumu kadar kısıtlayıcı ya da baskılayıcı olmasa da belki ondan fazla biçimlendiricidir ve dahası bu formülasyon bir baskıdan ziyade özgürlük ve irade söylemleri üzerine kuruludur. Gözetim artık klinik, tımarhane veya cezaevi yoluyla gerçekleşmemektedir. Aksine artık sokağa inmiştir. Gözetleyici olan iktidar değil; artık toplumun kendisidir. Modern bireyin trajedisi gözetlenirken; kendisini de kaçınılmaz bir gözetlemenin öznesi olarak bulmasındandır. Bu bitmeyen bir karşılaştırma ve kolektif huzursuzluk halinin de membaıdır. Modern toplumu hasetçi ve hasede zorlayıcı olarak okuyan Richard Sennett (2003) haksız değildir. Yaşamın her yerinde modern birey kendisi hakkında devamlı bir performans ve başkası hakkında devamlı bir duygulanıma tabi tutulur. "Yes, we can" (evet, yapabiliriz), performans toplumunun karakterini yansıtır. Fakat bu, depresif mağluplar kitlesinin özüdür de aynı zamanda (Chul-Han, 2015, s. 8). Elena'nın sürekli baktığı ayna bu depresyon halini, üstelik yaşamın her yerine yayar.

Ayna bir gölge ya da bir öteki-ben gibi, sergilenen performansı sorgular. Ayna, bedeni dışsallaştırarak kendisine ikincil fakat kontrol edici göz misyonu yükler. Linda'nın kaydolduğu zayıflama kulübünde neredeyse hiçbir aynanın olmaması tesadüf mü? Alışveriş merkezleri ve fitness salonlarındaki gibi içbükeyleştirilme suretiyle kısmen ince göstermediği müddetçe ayna, beden hakkında patavatsızca konuşabilen bir öteki bendir. Onların üzerinde kolayca hâkimiyet kurarak; kendisini oraya, belki de bakılan bedenin yerine kalıcı olarak ikame edebilir. Bakılmak istenmeyen ayna, bedeni her yerde takip eder. Sokakta, ofiste ya da tuvalette, her nerede olursa olsun, beden bu ayna-gözün perspektifine kilitlenir. Özne (bakan) ile nesne (baktığı) bu noktada yer değiştirir. Sanki izleyen gerçek-ben değil de; aynadaki yansımadır. Bu aynadaki-ben veya ayna-ben harekete geçiricidir. Ayna, öznenin kendisini temaşa etmesinin ötesinde ona hayaller ve arzular yükleyebilen bir tür düzenleyicidir (Baudrillard, 1998, s. 106). Aynadaki yansımada, toplumun kolektif standartları, beklentileri ve ayrıştırmaları tecelli eder. Ayna, içinde bulunduğu çağın hâkim ve geçerli diliyle konuşur. O güne özgü modanın kurallarını fısıldar. Diyet toplumu aynaların insanileşip; insanların aynalaştığı mübadele temelli, kolektif biçimde paylaşılan ve elbirliğiyle yürütülen hareketli bir düzeni ifade eder.

Bedeni tehditvari bir üslupla ideal ölçülere davet eden beden endüstrisi, mutlak yenilgi ve depresyon karşısında, hap kadar kolay yutulabilir basit formüllerle çözümler üretmeye çalışmaktadır. Bu hap toplumunun üyelerinden beklenen tıbbın koyduğu dogmatik kurallara uyması ve ölçülere harfiyen ittiba etmesidir. Beden, bu anlamda, özellikle tıbbın elinde sürekli olarak yeniden üretilmektedir. Görünüşle oynayan estetik operasyonlara şimdi de mide küçültme ameliyatları eklenmiştir. Bedenin kendisi yapaylaştıkça; onu düzenleyen araç ve uygulamalar da akıl-dışılaşmaktadır. Tıbbın kontrolünde beden, bir tür yapboz tasarıma evrilmiştir. Beden artık yapılabilir-yıkılabilir projedir ve tercih, bedenin sahibinin/ taşıyıcısının elindeymiş gibi sunulur. Oysa bu 'irade sende' ya da 'karar senin' yanılgısının ardında, varoluşu sürekli eksik, bedeni ise daima bozuk görme/gösterme eğilimi vardır ve 
bu eğilim büyük zayıflama endüstrisinin varlık sebebidir. Foucault'ya göre (1979'dan akt. Turner, 1995, s. 13), tıp faydalı ve zararlılar listesini belirleyerek içten içe neyin iyi neyin kötü olduğunun ölçütüne dönüşmüştür. Seçkinci bilim, zamanla aklın standartlarını oluşturarak ve kutsayarak gündelik yaşamı işgal etmiştir. Zararlı maddeler ve alışkanlıklarla istila edildiği kabul edilen beden (Bauman, 1999, s. 46), ancak tıbbın bilimsel, güvenilir ve hesaplanabilir yöntemleriyle arındırılıp istendik şekle sokulabilir gibi görülür. Belki de bu yüzden tıbbın beden üzerinde uyguladığı kural ve yöntemler makul değilse de, bir şekilde meşru görülür (Moulin, 2006, s. 15). Hastane koridorlarını aşan tıp, yine Foucault'nun da altını çizdiği gibi (1979), bu düzenin işleyişini sağlayan en belirleyici mekanizmadır. Tıbbın toplumsal değişim ve ilişkileri üzerindeki etkisinin yüceliğinden olsa gerek, sosyoloji, Foucault'ya göre, tıp sosyolojisinin bir alt dalıdır (Turner, 1995, s. 12).

\section{Sonuç}

Moulin'e göre (2006, s. 15), 20. yüzyılda bedenin tarihi, insanın bedenin kontrolünü kaybedip sonra yeniden ele geçirmesinin tarihidir. Oysa 21. yüzyılda beden yine elden çıkmıştır. Bugün, gerçekten kime ait olduğunu söylemek güç. Bedenin aldığı bu yön ne çizgisel; ne döngüseldir. Aksine olabildiğince sürprizlerle ve tesadüflerle dolu olan beden, dünyaya aniden ve hızla yayılan yeni formülleri kolayca içselleştirilebilir. Bu açıdan, beden hakkında, Turner'ın önerdiği gibi $(1995$, s. 236) statik bakıştan sakınmak ve bunun yerine bedenîleşmenin devam eden bir süreç ya da dağınık döngü olduğunu fark etmek gerekmektedir. Bununla birlikte Turner'ın, "insan bedendir" eleştirisini (1995) tersine çevirmek daha yerinde olabilir. Bugün ideal bedenden anlaşııması gereken, büyük oranda ideal bireydir. Kişinin bedeniyle yüzleşmesi, ontolojik manada kendi kendisiyle yüzleşmesi demektir (Michaud, 2006, s. 357). Çünkü o ten ve tin arasındaki tüm mesafeleri yok kılmaktadır. İnsanın içi dendiğinde akla ruhtan ziyade iç organların gelmesi bundandır (2006, s. 354). Beden, an itibariyle, bir felsefe sahası, hatta bir varoluş meselesidir.

Beden, cismani boyut ve tensel algılamadan sıyrılarak, bugün insanoğlunun aşkın niteliklerini üstlenmiş̧ir. Bu, sıradan bir indirgemenin ötesinde, bir çeşit ontolojik değiş-tokuştur. Beden politikasında herkes bir diğerinin kaderidir. Tıpkı farklı karakterlere ama iç içe hikâyelere sahip Matilde, Elena, Linda ve Gustavo gibi. Beden oyununa dâhil olan herkes, Malos Habitos filmindeki gibi, bir diğerinin varoluşunu yeniden formatlar. Bu noktada beden, Foucault'nun iddia ettiği gibi gözetlenen; ama daha da fazla gözetleyendir. Esasında beden-gözü kendisinden çok başkasına dönüktür. Elena gibi, yalnızca kendi bedeniyle ilgileniyormuş gibi gözükse de başkalarını da kontrol etmektedir. Fakat bu kontrol amaçsız bir fantezi değildir; aksine başkaları denen bu ayna, bireyin kendi bedenine açılan yoldur. Daha açık bir ifadeyle, modern birey kendi bedenine ya başkaları açısından ya da kendinebir-başkası olarak yaklaşmaktadır.

Beden endüstrisi, metaforik olarak, kendisini de yiyerek büyüyen bir canavara benzetilebilir. Yeni olan, belirdiği andan itibaren kaybolmaya başlar. Her şeyi demode olma şartıyla modalaştırarak 'yeni' kavramının içini boşaltır. Her ürünler eskime ve yok olma vaadiyle piyasaya sürülür. Sürdürülebilir olması gereken ürün ve hizmetler değil; tüketimin, dolayısıyla üretimin kendisidir. Beden politikasında üretimin devamlılı̆ı kusurların vurgulanmasına; sürgityinelenen ürün ve hizmetlere; ve bunların yenilenmiş sunumlarına dayanır. İmkânsız kusursuzluk miti, bu endüstrinin en değerli imkânını teşkil eder. Beden rejiminin öngörülemez 
güzergâhı karşısında yapılabilecek şey, belki de ideal beden mitini ve ölçülerini tümüyle görmezden gelmek, ona karşı tepkisizleşmektir. Modern bireyin öldürdüğü Tanrı'nın yerine sağlığı ve bedeni koyacağını öngörebilen Nietzsche'nin de belirttiği gibi (2007, s. 13-14), tepki göstermek tükenmeye yol açar. Beden üzerindeki her vurgu —ister ona sığınma ister ondan kaçış şeklinde olsun- tensel olanın tinsel olanın yerini almasını pekiştirmekten başka bir işlev görmez. Bu sebeple, sonuç olarak, bedene, tıpkı yemek gibi, kendi basit araçsallığı içinde yüzeysel ve abartısız bir bakış geliştirmeyi öneriyorum.

"Kendi bedenini kendin yarat" söylemi, özgürleştirici ifadenin yanında örtük şekilde kalıplaştırıcı ve zorlayıcıdır (Özbay, Terzioğlu ve Yasin, 2011, s. 18). Zorlayıcıdır çünkü "yapabilirsin" demek, aynı zamanda "yapmalısın" da demektir. Yapmalısın çünkü söz konusu beden-döngüsü ya da bedenin geri-dönüşüm endüstrisinin sürdürülebilirliği tam da bu gönül okşayıcı telkinde gizlidir. Buna bağlı olarak açıkça belirtmek gerekir ki, bedenle ilgili çalışmaların dönüp dolaşıp popüler manada özgürlük kavramına indirgenmesi de bu kışkırtıcı sorunsalın açmazlarından biri, belki de en önemlisidir. Bu noktada, bedensel özgürleşme söylemi, gerek Elena gerek Gustavo gibi, açık ve fiziksel baskı uygulamalarına kıyasla daha karmaşık ve daha parçalayıcıdır. Son yıllarda Türkiye'de özellikle kürtaj tartışmaları ekseninde kullanılan "benim bedenim, benim kararım" gibi ifadeler de, kanımca, bu bağlamda okunmalıdır. Her türlü transformasyonu mümkün ve gerekli gören bu yeni özgür beden efsanesi, esasında tam kendi iddiasının aksini kutsar; bedeni kolayca güdümlenebilir, kontrol edilebilir ve yönlendirilebilir kılar. Bedene atfedilen tüm özgürlük kıstasları, bedeni kendi sahibinden alarak; dışsal uyarıcıya dönüşen binlerce sahibin sıklıkla birbiriyle çelişen ve hızla değişen formüllerine teslim eder. "Bedenine sahip çık" önermesi de, benzer şekilde, bedeni muhafazakâr, gelenekçi ya da pastoral norm ve sınırlandırmalardan kurtarmayı maksat edinirken, onu kontrolsüz bir şekilde taşıyıcısının dahi tahayyül ve tayin edemeyeceği ve kendisine dikta edilen sürekli-değişim çağrısına — daha açık ifadeyle tüketim endüstrisinin kollarına bırakır. Bu sebeple bu özgürlük mitinin, bir yandan bireyselleşmenin ulviliğinden bahsederken; öte taraftan, bedeni kolektif idealler ekseninde ortaklaşa tüketilir hale getireceğini kestirebilmek ve bedeni, özgürleşmenin ön şartı olarak kuran bu modern yazılımı yok saymak gereklidir.

Beden hakkında esaslı bir duruş sergilemenin olmazsa olmazı, daha yeni olanın her zaman daha iyi olanı ifade ettiğini vaaz eden pazar klişelerine sırt çevirmektir. Beden kendi başına bir anlama dönüşemeyecek denli geçici ve kırılgandır; bu sebeple bedeni yaşama; yaşamı da salt bedensel olana indirgemek yerine, ona ruh üfleyici bir anlam katmak gerekmektedir. Bu konuda kadim medeniyet birikiminin bugüne kalan en ufak değer kıııntısı dahi, akışkan modernitenin telkin ettiği mutluluk ve özgürlük vaatleriyle bezenmiş yaşam-tarzından daha güvenilirdir, daha insanidir. Çünkü riyazet felsefesi, tüm düşünsel çıkarım ve pratiklerinde olduğu gibi ölümü merkezîleştirir ve ölümün bedeni eninde sonunda ele geçireceğini bilir. Bunun için bedeni müphem olan yaşamın değil; mutlak olan ölümün gölgesinde ele alır. Buna göre beden, tam olarak yok sayılamayacak kadar var; mutlak kalıcı anlamda var sayılamayacak denli de uçucudur. $\mathrm{O}$, kendisiyle sadece kendisi için savaşılmaya değmeyecek kadar değersiz; kendisi için yaşanmayacak denli sadakatsizdir. Emanet bedenin kutsiyeti, bedenden değil; emanet oluşuyla ilgilidir. Zira tek başına beden, nefsani olanın gösterdiği arzunun hamalıdır. Riyazetse, ölçülebilir bir form değişikliğinden ziyade görünmez olan ruhun tekâmülüne cevap arar. Oysa diyet çağı, görünmez olanı sınır dışı etmiştir. Bedensel 
teşhiri teşvik eden diyetizm, var olmanın yerini görünme ile doldurmuştur. Her şey göründüğü kadar vardır. Bir zamanlar, olmak, bedeninde kaybolmak anlamına gelirken, şimdiyse görünmek olma'ya denktir. Öte yandan, muhtevanın yıkımına denk düşen bu bedenîleşme hali filmin belki de son sahnesidir. Mahremiyetin çözülüşü teşhirci toplumun zaferi değil yitimidir; çünkü gizlenecek bir şey kalmadığında gösterilecek de bir şey kalmamış demektir. Bu şartlar altında çağdaş beden endüstrisinin karşısında iki yol vardır: Ya kendisini ilga etmek ya da yeniden mahremiyeti değerlileştirip bedeni bezginlik verici pornografik teşhirin kollarından kurtarmak; yani filmi başa sarmak. Kendi bedeniyle ve kendisi gibi olmayanların bedenleriyle ölümüne savaşan insanlarla dolu olan bu dünyanın şayet sonu gelmediyse, ben yeniden bir mahremiyet çağının kaçınılmaz olduğunu düşünüyorum. 


\title{
From Asceticism to the Modern Diet Society: The Body between Sanctity and Nonentity
}

\author{
Sertaç Timur Demir*
}

\section{Introduction}

In the modern diet society, the self is embodied (Giddens, 1991, p. 56), the body corresponds to the Dasein, and the skin refers to a transcendent reality. The vague body is, in this sense, a sort of gap that can be filled with endless possibilities. As Michaud (2006, p. 357) explains, it has simply become a naked and expressionless space that is continuously being disciplined in the shade of fashion norms. During the age of asceticism, however, the body was treated with self-discipline for the purpose of prioritising spiritual perfection. According to that philosophy, the body is the crucial point at which earthly desires and passions come into existence. The target of dieting in modern culture is to look well and to keep fit, while the ascetic view interprets it as a way of moral reclamation. Recently, one could claim that there is an uncontrollability and ambivalence about the body. In this sense, anorexia implies bodily nihilism while, on the other hand, obesity indicates the limitlessness of being. The body is no longer an external affair (Becker, 1995, p. 34), but an existential playground of modern identities. For this reason, this paper deals with the body and the notion of eating in the context of thinness, discipline, disorder, the biomedical industry, and the self through the film Malos Hábitos.

Malos Hábitos (Bad Habits), directed by Simón Bross in 2007, is essentially about eating and the body. The four characters, namely, Matilde, Elena, Linda and Gustavo, have intersecting stories. Matilde is a nun who establishes a common point between faith and hunger. Elena is anorexic, while her daughter Linda is obese. Elena loses her husband Gustavo to both anorexia and obesity. In the film, the body, which was once seen as a counter-metaphor of freedom, is depicted as one of the most challenging deadlocks of modern society. For Foucault (1977), the body is located in the middle of power relations not only as an instrument of possible punishment, but also as a form of private property and an object of investment. Despite this, it loses its value with each passing day (Lefebvre, 2005, p. 128). Life and death are neither for nor against the body — rather, they are with and within it.

* Assist. Prof., Gümüşhane University, Faculty of Communication, Department of Radio TV and Cinema. Correspondence: stdemir@gumushane.edu.tr Address: Gümüşhane Üniversitesi Yerleşkesi, İletişim Fakültesi Radyo TV ve Sinema Bölümü, Bağlarbaşı Mah., Merkez, Gümüşhane, Turkey. 


\section{The Principles and Institutions of the Body}

The film shows that the body is a constructive fiction. Thinness in this fiction is, beyond physical measure, a kind of representation of the modern age - so much so that, if achieved, it is seen as a requirement for having self-confidence, being part of the upper strata (Hesse-Biber, 2007, p. 115), being attractive (Haworth-Hoeppner, 2013, pp. 97-102), being healthy (Isono et al., 2009, p. 128), and being free (Fraser, 2009, p. 13). The ideal body is seen as being thin and white (Baker, 2015, p. 45), Euro-, and to a certain extent, Anglo-centric (Burns-Ardolino, 2009, p. 273). Being fat, on the other hand, indicates banality, ugliness, and laziness. Indeed, according to the modern discourse, weight is a moral issue (Hesse-Biber, 1996, p. 11). Modernity both creates and curses obesity, which, in turn, is both the main customer and potential enemy of modern life. Furthermore, according to Baudrillard (1999, p. 27), obesity is an expression of nihilism, a prototype of hyper-reality, and exempted from sex and sexualisation.

Weight is linked to death; therefore, there is a connection between being thin and desiring to live a long life. In any case, since there is no permanent solution to death, the best way to struggle against it is to try to escape from the impressions of agedness by being thin, just as Elena does in the film. Under this regime, medical advice is supreme. Nevertheless, the body also has no final form. This is the essence of medical industry, for one's target weight is always in the distance. This is also the essence of modern desperation, for all of the promised beauty myths proffered on the screen are volatile. Accordingly, the relationship between plastic surgery and the screen is not accidental. The media canonises thinness (Perse, 2001, p. 184), incites the people's dissatisfaction with their own bodies, and naturalises collective comparison (Fischer et al., 2006, p. 162). This is perhaps the primary step towards individual anxiety and social frustration. The body is frequently seen as being faulty and deficient, which is precisely what Linda feels in the film.

Every unit, object, and relationship in modern society has a significant relationship with the body. From hospital to school, from family to friends, from science to technology, and from screen to street, each corner of present-day culture reproduces and is reproduced by the same mechanism. All of the characters, socio-cultural environments, and economic networks depicted in the film represent this liquid system. Everybody is paradoxically alone in this collective organisation. Elena loses her social relationships as long as she focuses on her body. Gustavo breaks all connections with his family. Linda becomes unhappy, and Matilde loses faith in her beliefs. Eating habits determine and destroy their future. This regime makes all citizens weight-watchers, for people define each other by using measurements of physical appearance. As Bauman indicates (1999, p. 46), they are like a choir singing the same songs.

They regularly organise slimming ceremonies and arrange their feelings accordingly, have similar prescriptions and route maps, hate each other but walk together, and are both teammates and arch rivals. Chul-Han proposes the term "performance society" to describe this mass phenomenon (2015, pp. 10-11). According to him this society, which no longer refers to a society of discipline, is a performance society that consists of sport centres, offices, skyscrapers, airports, banks, shopping malls, and gene banks. Once upon a time, freedom was one's raison d'être; now, however, it is a sort of captivity. Weight-watchers 
in this society are not powerful, but simply ordinary people. Modern society is, as Sennett points out (2003), assertive and jealous. Everybody interiorises the motto "yes, we can" (Chul-Han, 2015, p. 8). The performance-based understanding, in turn, turns people into members of a mirror society.

Just like in Elena and Linda's lives, the mirror plays the role of an other-self, a kind of second and upper-eye. That is, perhaps, the reason why all slimming and beauty clubs are full of mirrors. Watching and being watched are constantly replacing one another. Under the influence of mirrors, the real-self and the watched-self become entangled only to the extent that the person looking into them has those collective expectations and standards. In the current diet society, the mirror and the individual fight and produce each other. The body industry plays a crucial role, for it determines and ceaselessly updates its ideal measures. These changing teachings are like pills that promise simple and quick solutions. In this respect, one can state that the body is now not only flexible, but also artificial. At the hands of medicine, it has been turned into a jigsaw puzzle and a game-like project.

\section{Conclusion}

In the twenty-first century, the body has gotten out of control. Today, although various strategies to reformulate the body exist, it is difficult to indicate the property's owner. This process is neither linear nor circular, but rather flexible and commutative. For this reason, the body cannot be comprehended by means of a static view. It is obvious that the human being has a body (Turner, 1995). On the other hand, the body is also human — so much so that the ideal body is somehow equivalent to an ideal personality. The body now ontologically involves the self. The soul and one's skin interlace each other. Hence, the body and its eating habits are not merely a gastronomic, but also a philosophical and even an existential, matter. It even transcends the notion of its own corporeality. This is not an ordinary evolution, but rather a vital exchange. In the politics of the body, everybody's fate is the fate of others, just like the fates of Matilde, Elena, Linda, and Gustavo, all of whom formulate one another. The mirror-eye captures individuals and forces them to transform at any moment.

The body industry can metaphorically be likened to a monster that grows by eating itself. Therefore, everything easily falls into decay. There is no room for permanence; nonetheless, object-like body components must always be new. But as the new involves endless impossibility, everything appears only to disappear in a vicious circle because the desired cult of perfectness is a figment of the imagination. For this reason, perhaps the only thing that should be done is to ignore the ideal measures determined by the popular culture industry. Thus, the best response against body politics is unresponsiveness. As Nietzsche underlines (2007, pp. 13-14), reaction causes exhaustion; therefore, I suggest that people embrace a superficial and plain view of the body. The discourse of "create your own body" is not emancipative, but oppressive (Özbay, Terzioğlu and Yasin, 2011, p. 18), because saying "yes, you can" simultaneously entails "but you should." The popular motto "it's my body and it's my decision" can also be read in this context, because the perspective that legitimises every kind of transformation indeed consecrates the exact opposite claim. Thus, the body can be controlled and manipulated by industrial regulations that are configured by means of earthly pleasures. 
The philosophy of asceticism is, however, based upon a worldview that highlights the importance of dying. Death is not something separate from life. The thought of dying is, therefore, the death of modern politics regarding the body. In contrast to the modern diet society, which emphasises the sovereignty of appearance, asceticism promotes the significance of being. In modern culture, things are able to exist as much as they appear. I believe, however, that this causes a loss of identity and the corrosion of privacy. If nothing is covered, then nothing is shown. Under these circumstances, the contemporary body industry has two ways forward: Either it should destroy itself or help save the modern body from the hands of pornographic display.

\section{Kaynakça / References}

Adorno, T., Horkheimer, M. (1997). Dialectic of enlightenment. Londra ve New York: Verso.

Ancet, P. (2008). Ucube bedenlerin fenomonolojisi. İstanbul: Yapı Kredi.

Baker, J. (2015). Things no one will tell fat girls: A Handbook for Unapologetic Living. California: Seal Press.

Baudrillard, J. (1993). The transparency of evil: essays on extreme phenomena. Londra ve New York: Verso.

Baudrillard, J. (1998). Symbolic exchange and death. Londra, Thousand Oaks ve Yeni Delhi: Sage Publications.

Baudrillard, J. (1999). Fatal strategies. London: Pluto Press.

Baudrillard, J. (2004). The Consumer society: myths and structures. Londra, Thousand Oaks ve Yeni Delhi: Sage Publications.

Bauman, Z. (1999). In search of politics. Cambridge and Malden: Polity Press.

Becker, A. E. (1995). Body, self, and society: the view from Fiji. Philadelphia: University of Pennsylvania Press.

Bross, S. (Yönetmen). (2007). Malos Hábitos. Mexico: Altavista Films, Fondo de Inversión y Estímulos al Cine, García Bross \& Asociados, Santo Domingo Films. [103 min].

Burns-Ardolino, W. A. (2009). Jiggle in my walk: The ironic power of the "Big Butt" in American Pop Culture. E. D. Rothblum ve S. Solovay (Ed.), The Fat studies reader içinde (s. 271-279). New York ve Londra: New York University Press.

Canetti, E. (2000). Crowds and power. Londra: Phoenix Press.

Castells, M. (2000). The Rise of the network society: economy, society and culture v. 1: The Information age: economy, Society and culture v. 1. Oxford ve Malden: Blackwell Publishers Ltd.

Castilho, S. M. (2006). Psychopathological Aspects of Body Disturbance on Anorexia and Bulimia Nervosa. P. I. Swain (Ed.), Anorexia Nervosa and Bulimia Nervosa: New Research içinde (s. 27-39). New York: Nove Science Publishers, Inc.

Chul-Han, B. (2015). The Burnout society. Stanford: Stanford University Press.

Cynthia L. O., Carroll M. D., Kit B. K., ve Flegan, K. M. (2014). Prevalence of Childhood and Adult Obesity in the United States, 2011-2012. The Journal Of American Medical Association, 311(8), 806-814.

Demir, S. T. (2014). The City on Screen: A Methodological Approach on Cinematic City Studies. CINEJ Cinema Journal, (4), 1.

Falk, P. (1994). The Consuming Body. Londra, Thousand Oaks, Yeni Delhi: Sage Publications.

Fedorak, S. A. (2014). Global issues: A cross-cultural perspective. Ontario, Plymouth ve New York: University of Toronto Press.

Fischer, S., Smith, G. T. ve Cyders, M. A. (2006). Integrating Personality and Environmental Risk Factors for Bulimia Nervosa. P. I Swain (Ed.), Anorexia Nervosa and Bulimia Nervosa: New Research içinde (s. 159-184). New York: Nove Science Publishers, Inc.

Food and Agriculture Organization of the United Nations. (2015). The State of Food Insecurity in the World. http:// www.fao.org/3/a4ef2d16-70a7-460a-a9ac-2a65a533269a/i4646e.pdf adresinden 22 Aralık 2015 tarihinde edinilmiştir. 
Foucault, M. (1971). Madness and civilization. Londra: Tavistock.

Foucault, M. (1973). The Birth of the clinic. Londra: Tavistock.

Foucault, M. (1977). Discipline and punish: The Birth of the Prison. Londra: Tavistock.

Foucault, M. (1979). The History if sexuality volume I: An Introduction. Londra: Penguin.

Fraser, L. (2009). The Inner corset: A brief history of fat in the United States. E. D. Rothblum ve S. Solovay (Ed.), The Fat studies reader içinde (s. 11-14). New York ve Londra: New York University Press.

Giddens, A. (1991). Modernity and Self-identity: Self and Society in the Late Modern Age. Cambridge: Polity; Oxford: Blackwell Publishing Ltd.

Global hunger index. (2015). Armed conflict and the challenge of hunger. http://www.welthungerhilfe.de/fileadmin/user_upload/Mediathek/Welthunger-Index/WHI_2015/global-hunger-index_2015_english.pdf adresinden 22 Aralık 2015 tarihinde edinilmiştir.

Göktaş, V. (2012). Modern İnsanın Bir İhtiyacı Olarak Riyazet ve Erzurumlu İbrahim Hakkı́nın Riyazetle İlgili Görüşleri. EKEV Akademi Dergisi, (16), 50.

Grodstein, F., Levine, R., Spencer, T., Colditz, G.A. ve Stampfer, M. J. (1996). Three year follow up of participants in a commercial weight loss program: can you keep it off? Archives of Internal Medicine, 156(12), 1302-1306.

Guthman, J. (2009). Neoliberalism and the constitution of contemporary bodies. E. D. Rothblum ve S. Solovay (Ed.), The Fat studies reader içinde (s. 187-196). New York ve Londra: New York University Press.

Haworth-Hoeppner, S. (2013). Medical Discourse on Body Image: Reconceptualizing the Differences between women with and without eating disorders. J. Sobal ve D. Maurer (Ed.), Interpreting weight: The social management of fatness and thinness içinde (s. 89-111). New Brinswick and London: Aldine Transaction.

Hesse-Biber, S. N. (1996). Am I thin enough yet?: The cult of thinness and the commercialization of identity. New York ve Oxford: Oxford University Press.

Hesse-Biber, S. N. (2007). The Cult of thinness. New York: Oxford University Press.

Higgins, E. T. (1987). Self-discrepancy: A theory relating self and affect. Psychological Review, (94), 319-340.

Isono, M., Watkins, L. P. ve Lian, L. E. (2009). Bon Bon Fatty Girl: A qualitative exploration of weight bias in Singapore. E. D. Rothblum ve S. Solovay (Ed.), The Fat studies reader içinde (s. 127-138). New York ve Londra: New York University Press.

Kaplan, Y. (2009). Felsefe öldü! Yaşasın sinema! (1)-(2) Yenişafak: http://www.yenisafak.com/yazarlar/yusufkaplan/felsefe-oldu-yasasin-sinema-1-17332 adresinden 5 Nisan 2016 tarihinde edinilmiştir.

Lefebvre, H. (2005). Critique of Everyday Life: Volume 3. Londra: Verso.

Michaud, Y. (2006). Görselleştirme: Beden ve Görsel Sanatlar [Visualisations: Le Corps et les Arts Visuels]. A. Corbain, J. J. Courtine ve G. Vigarello (Ed), Bedenin Tarihi 3 Bakıştaki Değişim: 20. Yüzyıl [Histoire du corps: Les mutations du regard] içinde (s. 343-357). İstanbul: Yapı Kredi.

Moulin, A. M. (2006). Tıbbın karşısında beden [Le corps face à la médecine]. A. Corbain, J. J. Courtine ve G. Vigarello (Ed), Bedenin Tarihi 3 Bakıştaki Değişim: 20. Yüzyıl [Histoire du corps: Les mutations du regard] içinde (s. 15-57). İstanbul: Yapı Kredi.

Naumark-Sztainer, D. (2005). I'm, like, so fat! New York ve Londra: The Guilford Press.

Nietzsche, F. (2007). Ecco Homo: how to become what you are. (D. Large, Çev.) Oxford ve New York: Oxford University Press.

Ory, P. (2006). Sıradan Beden [Le corps ordinaire]. A. Corbain, J. J. Courtine ve G. Vigarello (Ed), Bedenin Tarihi 3 Bakıştaki Değişim: 20. Yüzyıl [Histoire du corps: Les mutations du regard] içinde (s. 105-129). İstanbul: Yapı Kredi.

Özbay, C., Terzioğlu, A. ve Yasin, Y. (2011). Neoliberalizm ve Mahremiyet: Türkiye'de Beden, Sağlık ve Cinsellik. İstanbul: Metis.

Perse, E. M. (2001). Media effects and society. New Jersey ve Londra: Lawrence Erlbaum Associates, Publishers.

Qvortrup, M. (2010). Social determinants of obesity. G. Tsichlia ve A. Johnstone (Ed.), Fat matters: from sociology to science içinde (s. 13-21). The Old Bakery, St John's Street, Keswick ve Cumbria: M\&K Publishing.

Seid, R. P. (1991). Never too thin: why women are at war with their bodies. New York: Prentice Hall Press. 
Sennett, R. (2003). Respect: The Formation of Character in a World of Inequality. Londra, New York, Victoria, Toronto, Yeni Delhi, Auckland ve Rosebank: Penguin Books.

Shilling, C. (1993). The Body and social theory. Londra: Sage Publications.

Smolak, L. (2011). Body Image development in childhood. T. F. Cash ve L. Smolak (Ed.), Body image: A handbook of science, practice, and prevention içinde (s. 67-76). New York: The Gulford Press.

Sundgot-Borgen, J., Torstveit, M. K. (2004, Ocak). Prevalence of eating disorders in elite athletes is higher than in the general population. Clin J Sport Med., 14(1), 25-32.

Synott, A. (1993). The Body social: symbolism, self and society. Londra: Routledge.

The Guardian (2015). Global obesity rise puts UN goals on diet-related diseases 'beyond reach'. http://www.theguardian.com/society/2015/oct/09/obesitys-global-spread-un-goals-diet-related-diseases-fail adresinden 22 Aralık 2015 tarihinde edinilmiştir.

Turner, B. S. (1995). Medical power and social knowledge. Londra, Thousand Oaks and Yeni Delhi: Sage Publications.

Twigg, J. (2011). Modern Asceticism and Contemporary Body Culture. E. Peeters, L Molle, K. Wils (Ed.), Beyond Pleasure: Cultures of Modern Asceticism içinde (s. 227-244). New York ve Oxford: Berghahn Books.

World Health Organisation. (2015). Obesity and overweight. http://www.who.int/mediacentre/factsheets/fs311/ en/ adresinden 23 Aralık 2015 tarihinde edinilmiştir. 